
\title{
25 Research Square \\ Experimental and Numerical Study on the Explosive Welding of Niobium-Steel
}

\section{Jian Wang}

Dalian University of Technology https://orcid.org/0000-0002-6218-5421

Xiao-jie Li ( $\nabla$ robinli@dlut.edu.cn )

Dalian University of Technology

\section{Yu-xin Wang}

Dalian University of Technology

\section{Research Article}

Keywords: explosive welding, niobium-steel composite plate, weldability window, numerical simulation

Posted Date: April 7th, 2021

DOI: https://doi.org/10.21203/rs.3.rs-377313/v1

License: (1) This work is licensed under a Creative Commons Attribution 4.0 International License. Read Full License 


\title{
Experimental and Numerical Study on the Explosive Welding of Niobium-Steel
}

\author{
Jian Wang a , Xiao-jie Li a,b,* ${ }^{\text {, Yu-xin Wang a }}$ \\ (a Department of Engineering Mechanics, Dalian University of Technology, Dalian, 116024, People's Republic of
}

China;b State Key Laboratory of Structural Analysis for Industrial Equipment, Dalian University of Technology,

Dalian 116024, People's Republic of China)

\begin{abstract}
The aim of this work is to study the use of explosive welding to produce Niobium-Steel composite plate, which is used in nuclear industry equipment material manufacturing. The welding parameters was determined by weldability window and numerical simulation was used to predict the wave shape of the welding interface. The morphology of the interface wave was observed by scanning electron microscope. Component measurement around interface waves. The experimental samples were investigeted using mechanical tests. The results show that the explosion parameters optimized by theory and numerical simulation can be used to obtain a niobium-steel composite plate with better welding quality. It can be proved that the welding quality is better by observing the interface wave and testing the mechanical properties, it can be seen that the melting zone of the welding interface is composed of niobium and steel by the composition analysis instrument. The morphology of the welding interface wave is consistent with the numerical simulation results, and the numerical simulation shows the changes of temperature, strain, and stress during the welding process.
\end{abstract}

Keywords: explosive welding; niobium-steel composite plate; weldability window; numerical simulation

\section{Introduction}

Niobium is a rare metal that has good properties such as high melting point $2477^{\circ} \mathrm{C}$, good corrosion resistance and low thermal neutron capture section. Niobium has a wide range of applications in the nuclear industry, so it is very important for the preparation of niobium composite materials. Explosive welding is one of the most common ways to combine dissimilar metals, especially for two or more metals with a large difference in melting point[1]. Explosive welding is a method of using the energy generated by the explosive detonation to drive the flyer plate, so that the flyer plate is accelerated and collided with the base plate in an oblique manner, generating a jet, thereby welding together[2]. Explosive welding can produce composite plates of different sizes according to industrial needs and bimetal composite panels are the most common. Lower-priced metals and relatively expensive rare metals with special physical and chemical properties are welded together by explosive welding, so that not only the composite plate has the characteristics of rare metals but also save costs. The common composite plates are Aluminum-Magnesium[[3],[4]], SteelTitanium[5], Tungsten-Copper[6] etc., which are widely used in industrial production and special industries. Explosive welding of clad tube[7] and multi-layer metal explosive welding [8] are also used in the production of composite plates.

\footnotetext{
* Corresponding author: Xiao-jie Li

E-mail: robinli@dlut.edu.cn
}

Tel/Fax: 86+041184706163 
G.H.S.F.L.Carvalho[9] found that the weldability of aluminum-copper explosive welding is improved when copper is used as a flyer plate. Ali Arab[10] performed explosive welding on AlCoCrFeNi high entropy alloys and Al-6061 and found that due to plastic deformation and grain refinement, the hardness of aluminum increases near the interface. Ming Yang[11] successfully welded $0.2 \mathrm{~mm}$ tantalum to the steel plate by explosive welding. In terms of explosive welding of thin plates, Qi Wang[12] successfully prepared AZ31B/AA5052 thin composite plate. I. A. Bataev [13] discussed the effect of cooling rate and pressure on the formation of amorphous alloys by explosive welding of low carbon steel-niobium. At present, commercial finite element software can simulate the explosive welding process and get good conclusions, Yan Li[14] simulated the whole process of TI-AL explosive welding by AUTODYN and found that the jet mainly came from the aluminum plate, which was consistent with the experimental conclusions. Xiang-yu Zeng [2] used the SPH method to simulate explosive welding and pointed out that the strength of the thermal conductivity effect increases as the size decreases. The performance of the composite plates largely depends on the shape of the welding interface. By changing the experimental parameters to change the speed of the collision point, the collision angle and other conditions, we can get different welding interfaces. The welding window [15] provides a parameter adjustment range. When the explosive welding experiment parameters are in the welding window, the experiment can be successful. The shape of the welding interface can be roughly divided into: straight area, small ripple area, large ripple area, and vortex area, of which the small corrugated area has the best performance [16].

This paper is mainly to study the feasibility of Steel-Niobium explosive welding composite plate, use optical microscope and microelectronic scanning electron microscope to characterize the interface, explore the wave shape of the welding interface, analyze the distribution of components around the interface, the tensile curve, and the tensile-shear curve. The finite element analysis software performs numerical simulation on the interface formation process.

\section{Niobium-steel welding window}

As shown in Fig.2.1, the detonation velocity of the explosive is $V_{d}$,during the explosive welding experiment, when the flyer plate driven by the energy of the explosive hits the base plate, it will bend, the angle of the bend is called the bending angle $\beta$. The flyer plate collides with the base plate at the collision velocity $V_{p}$. The moving speed of the collision point between the flyer plate and the base plate is $V_{c}$. When the flyer plate and the substrate are placed in parallel, $V_{c}=V_{d}$. The geometric relationship of $\beta, V_{p}$, and $V_{c}$ is shown in Eq.(2.1).

$$
V_{p}=2 V_{c} \cdot \sin \frac{\beta}{2}
$$

According to Eq.(2.1), it can be seen that as long as any two variables among $\beta, V_{p}$, and $V_{c}$ are determined, the remaining variable can be determined. 


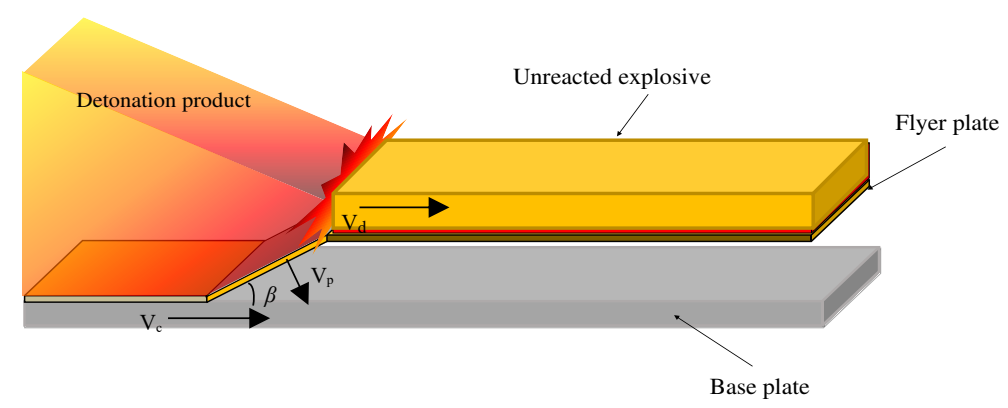

Fig. 2.1 Schematic diagram of explosive welding process

The most commonly used welding window is shown in Fig.2.2. In the coordinate system formed by the collision speed $V_{p}$ and the collision point moving speed $V_{c}$, it is composed of four boundary lines:

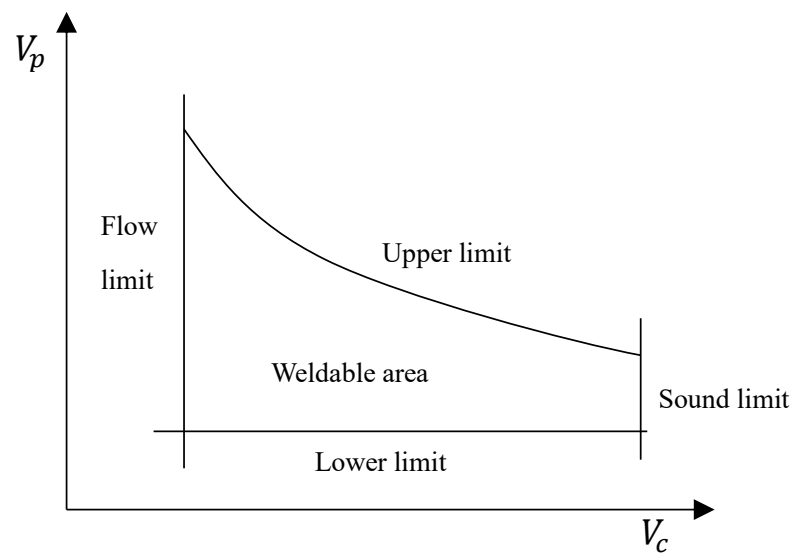

Fig.2.2 Explosive welding window

(1) Lower limit: The jet flow at the collision point is a necessary condition for successful welding, therefore, the collision velocity $V_{p}$ needs to be greater than the minimum collision velocity $V_{p m i n}$ to produce jet.

(2) Flow limit: The collision point velocity $V_{c}$ must exceed the minimum value $V_{c m i n}$ to produce jet.

(3) Sound limit: The velocity of the collision point $V_{c}$ should be less than the sound velocity of flyer plate and base plate, otherwise the generation of jet will be inhibited.

(4) Upper limit: In order to prevent excessive welding interface energy. When the collision energy is too large, excess energy will be deposited on the interface. When the reflected wave reaches the interface, the interface is still in a molten state and the welding interface will be separated.

\subsection{Lower limit of explosive welding}

Various theoretical formulas for the lower limit of explosive welding have been proposed in the early explosive welding research. The lower welding limit formula Eq.(2.2) proposed by Deribas[17] in 1971 is the most widely used.

$$
\beta=K \sqrt{H V /\left(\rho v_{f}^{2}\right)}
$$


Where $: \beta$ is the lower critical angle at which explosive welding can produce "re-incident flow", $K$ is a constant, the value of $K$ is determined by the cleanliness of the surface of explosive welding materials, when the surfaces treatment of the flyer plate and the base plate are clean, $K=0.6 . H V$ is the Vickers hardness of the material. $\rho$ is the material density. $V_{f}$ is the incoming flow velocity, when the flyer plate is placed parallel to the base plate, $V_{f}=V_{d}$.

When $\beta$ is relatively small, Eq.(2.1) can be rewritten as $V_{p}=2 V_{c} \cdot \sin \frac{\beta}{2}=V_{c} \beta=V_{d} \beta$, then Eq. (2.2)can be rewritten as

$$
v_{p \min }=K \sqrt{H V / \rho}
$$

For the minimum collision pressure of the interface, the equivalent normal shock wave model is adopted[18]:

$$
P=\rho c \frac{v_{p \min }}{2}
$$

Where: $c$ is the sound velocity of the metal material.

For explosive welding of dissimilar materials, the minimum collision velocities $v_{p \min 1}$ and $v_{\min 2}$ and the corresponding minimum collision pressures $P_{\min 1}$ and $P_{\min 2}$ of the two materials can be calculated by Eq.(2.3) and Eq.(2.4), the condition for simultaneous generation of bimetallic jets is that the interface collision pressure is greater than the minimum collision pressure of the two metals, let $P_{\min }=\max \left(P_{\min 1}, P_{\min 2}\right)$, the minimum collision velocity of jet produced by dissimilar metals is:

$$
v_{p \min }^{b i}=P_{\min }\left(\frac{1}{c_{1} \rho_{1}}+\frac{1}{c_{2} \rho_{2}}\right)
$$

Where: $c_{1}$ and $\mathrm{c}{ }_{2}$ are the speed of sound of the base plate and the flyer plate, $\rho_{1}$ and $\rho_{2}$ are the density of the base plate and the flyer plate, respectively.

\subsection{Explosive welding flow limit}

The flow limit of explosive welding should be the condition that the jet is just generated at the collision. The theoretical stagnation point pressure must be much greater than the strength of the material itself, so that the material can reach the flow state. The stagnation point pressure in the flow state should be greater than 10 times the tensile strength of the material, the flow limit of a single metal can be expressed as:

$$
\begin{aligned}
& P_{c}=\frac{\rho v_{c}^{2}}{2} \geq 10 \sigma_{b} \\
& v_{c \text { min }}=\sqrt{20 \sigma_{b} / \rho}
\end{aligned}
$$

For bimetals, the stagnation point pressure is determined by the lower density, and the successful welding requires that the stagnation pressure must be greater than the higher strength. So Eq. (2.6) and Eq. (2.7) can be changed to:

$$
\begin{gathered}
P_{c}=\frac{\rho_{\min } v_{c}^{2}}{2} \geq 10 \sigma_{b \max } \\
v_{c \text { min }}=\sqrt{20 \sigma_{b \max } / \rho_{\min }}
\end{gathered}
$$

Where: $\rho_{\min }$ is the smaller density of the two metals; $\sigma_{b \max }$ is the higher strength of the two metals. 


\subsection{Sound speed limit of explosive welding}

The speed of the collision point is less than the sound speed of the base material, so the calculation formula of the sound speed limit is:

$$
v_{c \max }=\min \left(C_{1}, C_{2}\right)
$$

Where: $C_{1}, C_{2}$ are the sound velocity of the base plate and the flyer plate respectively.

\subsection{The upper limit of explosive welding}

In order to prevent the occurrence of over-melting failure, Wittman[19] proposed the following upper limit formula for explosive welding:

$$
v_{p \max }=\frac{1}{N_{w}}\left(\frac{T_{m} C_{0}}{v_{c}}\right)^{\frac{1}{2}}\left(\frac{\lambda C_{p}}{\rho h C_{0}}\right)^{\frac{1}{4}}
$$

Where: $N_{w}$ is a constant of $0.1, T_{m}$ is the melting temperature of the metal; $\lambda$ is the thermal conductivity; $C_{p}$ is the specific heat capacity; $\mathrm{h}$ is the thickness of the flyer plate. The original formula is $v_{p \max }=\frac{1}{N_{w}}\left(\frac{T_{m} C_{0}}{v_{c}}\right)^{\frac{1}{2}}\left(\frac{\lambda C_{0} C_{p}}{\rho h}\right)^{\frac{1}{4}}$, whose dimension is wrong.

\subsection{Niobium-steel explosive welding window}

According to the physical properties of niobium and Q235 steel, the calculated welding window is shown in Fig.2.3.

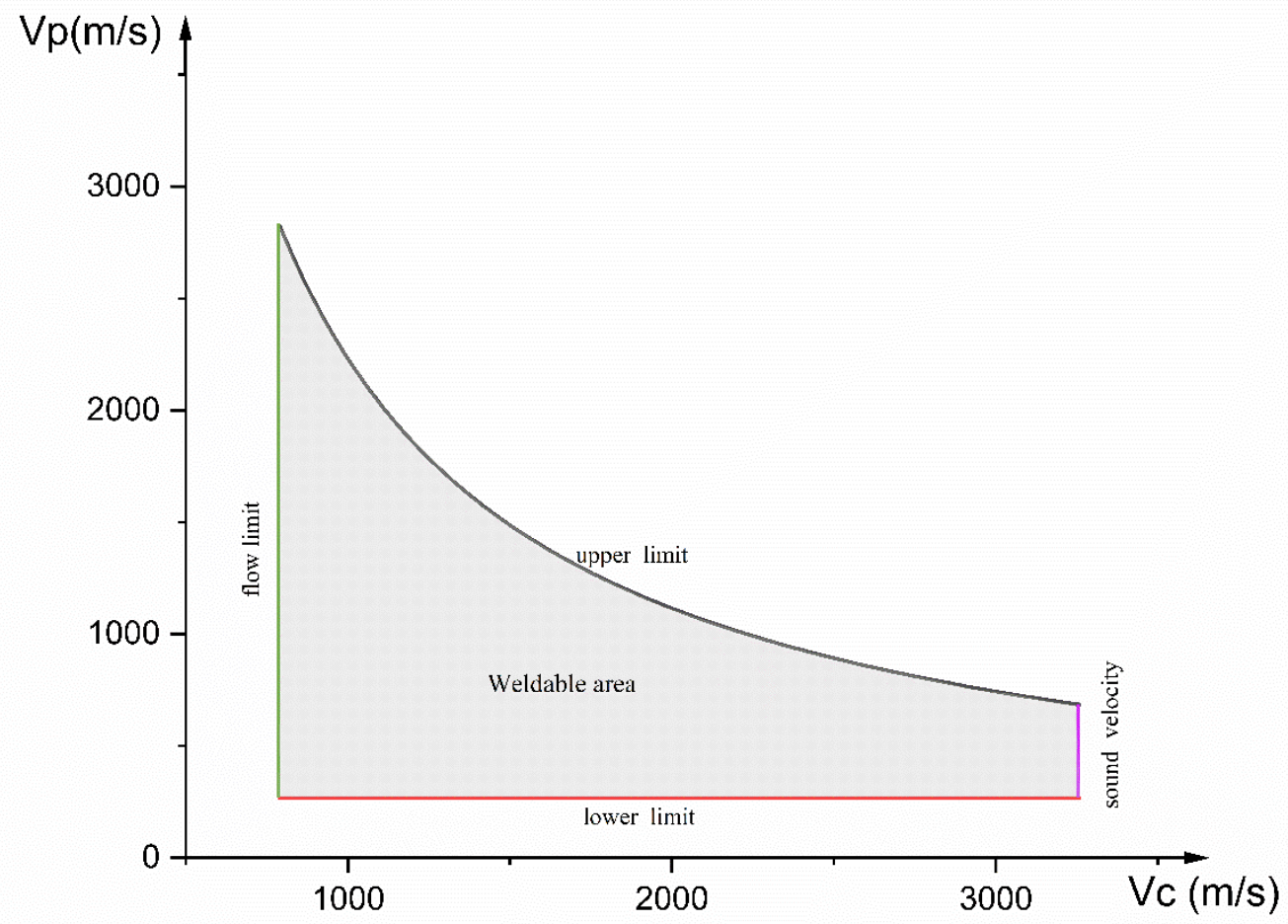

Fig.2.3 Niobium-Steel explosive welding window

According to Fig.2.3, the explosive parameters are selected as the detonation velocity $V_{d}=$ 
$2800 \mathrm{~m} / \mathrm{s}$, the density $\rho_{0}=0.9 \mathrm{~g} / \mathrm{cm}^{3}$, the explosive thickness $\delta_{0}=30 \mathrm{~mm}$, and the polytropic index $\mathrm{K}=2.0$, the flyer plate $\rho_{1}=8.57 \mathrm{~g} / \mathrm{cm}^{3}$, the thickness of flyer plate $\delta_{1}=3 \mathrm{~mm}$, the mass ratio of the charge can be calculated:

$$
\mathrm{R}=\frac{\rho_{0} \delta_{0}}{\rho_{1} \delta_{1}}=\frac{0.9 \times 30}{8.57 \times 3}=1.05
$$

Under the above conditions, the relationship between height $\mathrm{y}$ which is the distance between the base plate and the flyer plate and the bending angle $\beta$ obtained according to the characteristic line difference method is shown in Fig.2.4.

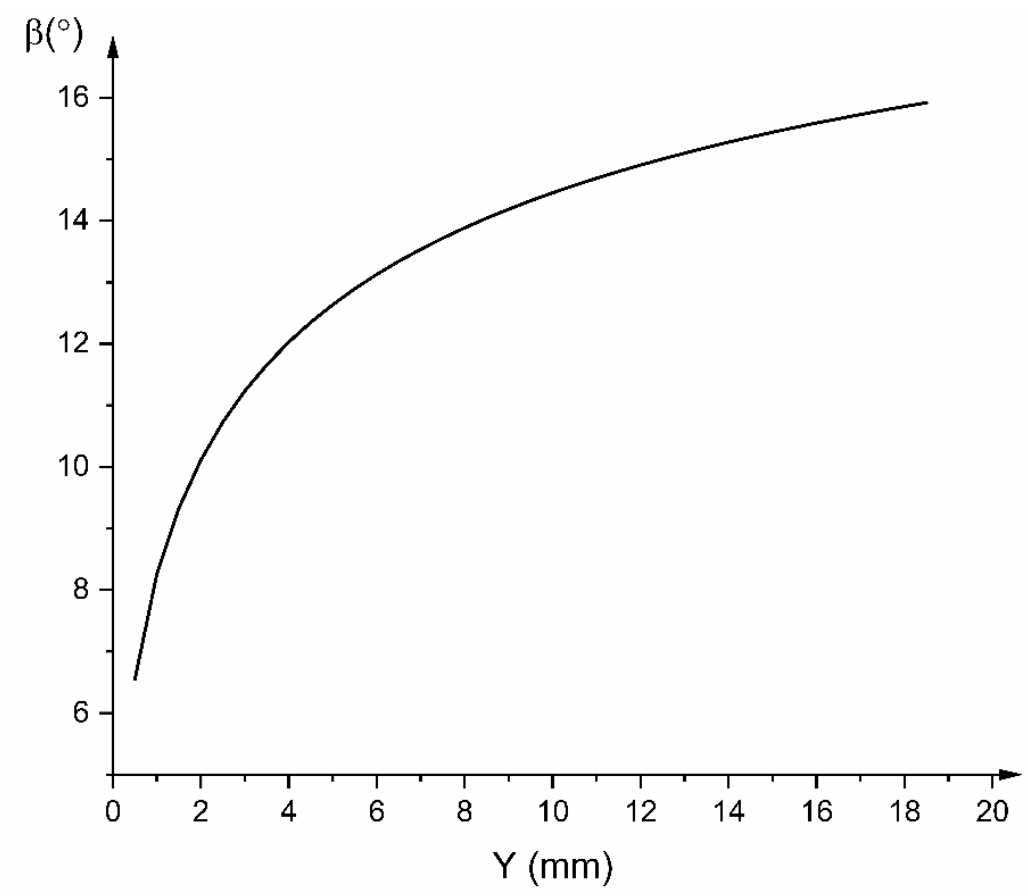

Fig.2.4 The relationship between $\mathrm{y}$ and $\beta$

According to the theoretical calculation, the explosion parameters shown in Table 2.1 are selected, and the calculated theoretical collision velocity $V_{p}=676 \mathrm{~m} / \mathrm{s}$, and the bending angle $\beta=$ $13.88^{\circ}$.

Table 2.1 The explosion parameters

\begin{tabular}{cccc}
\hline $\begin{array}{c}\text { explosive thickness } \\
/ \mathrm{mm}\end{array}$ & $\begin{array}{c}\text { detonation velocity } \\
/\left(\boldsymbol{m} \cdot \mathrm{s}^{-1}\right)\end{array}$ & $\begin{array}{c}\text { explosive density } \\
/\left(\mathrm{g} \cdot \mathrm{cm}^{-3}\right)\end{array}$ & $\begin{array}{c}\text { height } \\
/ \mathrm{mm}\end{array}$ \\
\hline $\mathbf{3 0}$ & $\mathbf{2 8 0 0}$ & $\mathbf{0 . 9}$ & $\mathbf{8}$ \\
\hline
\end{tabular}

\section{Experiment}

In this experiment, the flyer plate is $3 \mathrm{~mm}$ thick niobium plate, and the base plate is $5 \mathrm{~mm}$ thick stainless steel plate. According to the welding window, select the explosion parameters as follows: the stand-off distance was calculated as $8 \mathrm{~mm}$, the ANFO explosive was selected with density of $0.9 \mathrm{~g} / \mathrm{cm}^{3}$ and the thickness of $30 \mathrm{~mm}$, and detonation velocity is $2800 \mathrm{~m} / \mathrm{s}$ approximately measured by a continuous velocity probe. The schematic illustration is shown in Fig.2.1. The niobium plate is composed of $100 \%$ niobium, and the composition of stainless steel is shown in Table 3.1. 
Table 3.1 Steel plate composition (wt.\%)

\begin{tabular}{lccccc}
\hline Element & $\mathrm{C}$ & $\mathrm{O}$ & $\mathrm{Si}$ & $\mathrm{Mn}$ & $\mathrm{Fe}$ \\
\hline content & 9.22 & 11.87 & 0.31 & 0.77 & 77.83 \\
\hline
\end{tabular}

\subsection{Experiment Results}

\subsubsection{Microstructure of the welding interface}

In order to better observe the welding interface, the surface of niobium and steel was pickled and corroded. The ratio of the corrosive solution is shown in Table 3.2. Because the niobium corrosive liquid has a strong corrosive effect on Q235, but the Q235 corrosive liquid has no corrosive effect on niobium, first etch the niobium, and then use the Q235 corrosive liquid to clean the Q235 surface.

Table 3.2 Ratio corrosion liquid

\begin{tabular}{ccccccc}
\hline & $\begin{array}{c}\mathrm{H}_{2} \mathrm{SO}_{4} \\
/ \mathbf{m l}\end{array}$ & $\begin{array}{c}\mathrm{HNO}_{3} \\
/ \mathbf{m l}\end{array}$ & $\begin{array}{c}\mathrm{HF} \\
/ \mathbf{m l}\end{array}$ & $\begin{array}{c}\mathrm{CH}_{3} \mathrm{COOH} \\
/ \mathbf{m l}\end{array}$ & $\begin{array}{c}\mathrm{FeCL}_{3} \\
/ \mathbf{g}\end{array}$ & $\begin{array}{c}\mathrm{HCL} \\
/ \mathbf{m l}\end{array}$ \\
\hline $\mathbf{N b}$ & 5 & 2 & 2 & - & - & - \\
\hline Steel & - & - & - & 17 & 1 & 3 \\
\hline
\end{tabular}

The microstructure of the niobium-steel welding interface was characterized by SEM as shown in the Fig.3.1. It can be observed in Fig.3.1a that the interface joint is relatively regular corrugated, and there are no holes or cracks. Compared with the flat welding interface, the interface of the microwave structure has better welding quality [20]. Observation of a single wave in Fig.3.1b shows that the amplitude is $280 \mathrm{um}$ and the wavelength is $483 \mathrm{um}$ by measurement and there is a melting and mixing area at the junction, The formation of the melting zone is mainly caused by the capture of the part of the jet formed at the interface by the base material because of the high-speed combination of flyer plate and base plate. Due to the high temperature and the mixing of two metals, the microstructure of the molten zone is usually more complicated, such as metal compound and amorphous, which will reduce the quality of welding[21].
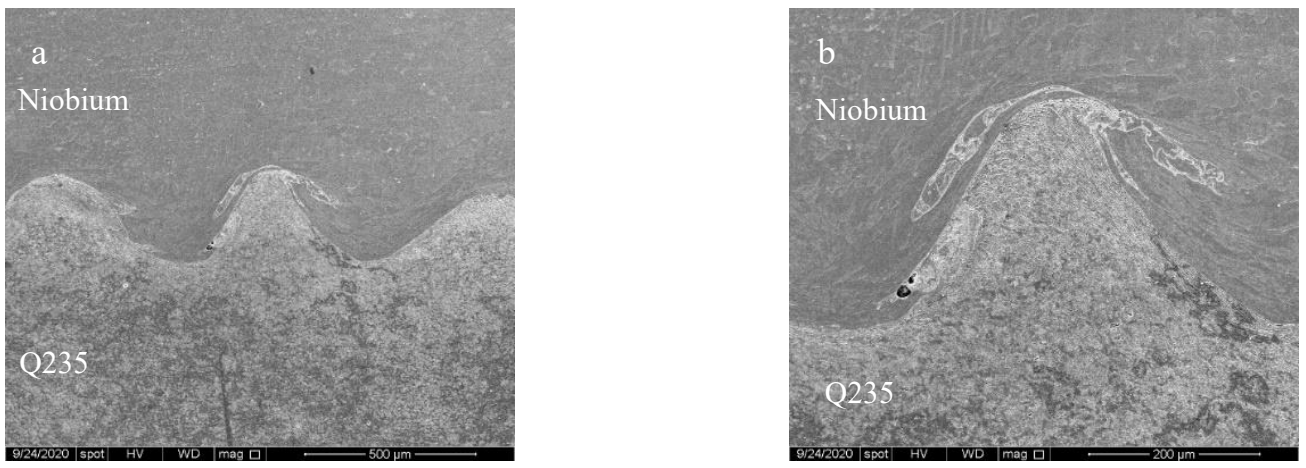
Fig.3.1 SEM image of Niobium-Q235 interface

\subsubsection{Elemental analysis}

The results of energy spectrum analysis and linear scanning at the interface are shown in the Fig.3.2, the yellow line in Fig.3.2a is the linear scanning area, and Fig.3.2b shows the composition distribution of niobium and steel, it can be seen that the energy width of the diffusion layer is $5 \mathrm{um}$, and the Brownian motion of atoms or molecules will produce a concentration gradient, thereby forming the diffusion layer. Under normal circumstances, the thickness of the diffusion layer is only a few microns[22].
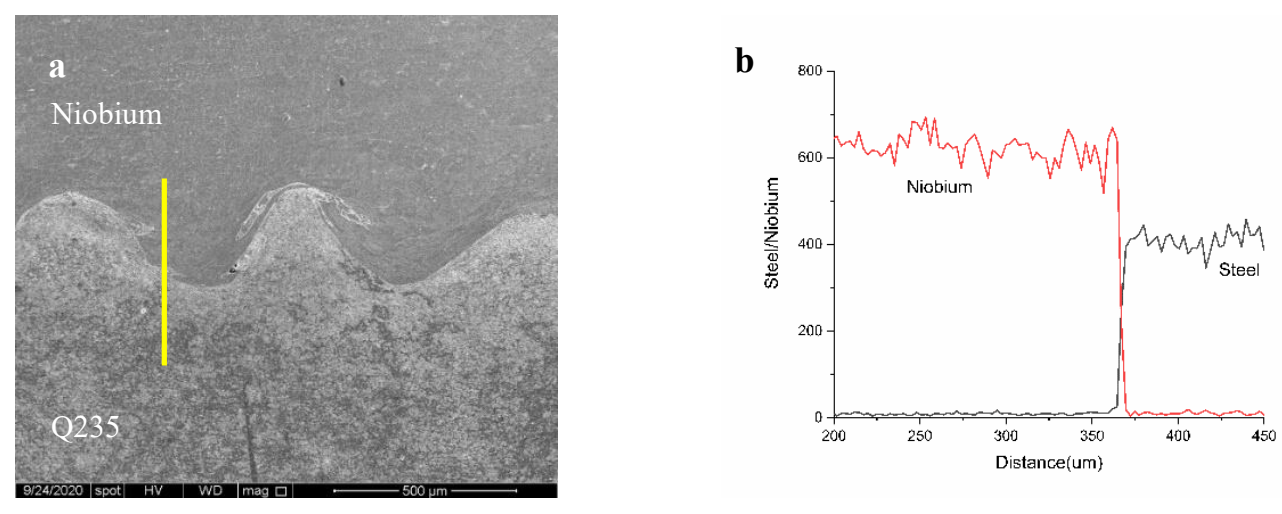

Fig.3.2 Elemental analysis image of Niobium-Q235 interface

\subsubsection{Mechanical properties}

The welding interface was characterize the morphology by scanning electron microscope (SEM). the composition distribution near the welding interface was detected by energy spectrum analysis. In order to explore the mechanical properties of composite plates, At room temperature, the specimens were subjected to tensile and tensile-shear tests (strain rate $2 * 10^{-4}$ ). The size of the specimen is shown in the Fig.3.3 (a. Tensile specimen b. Tensile-shear specimen)

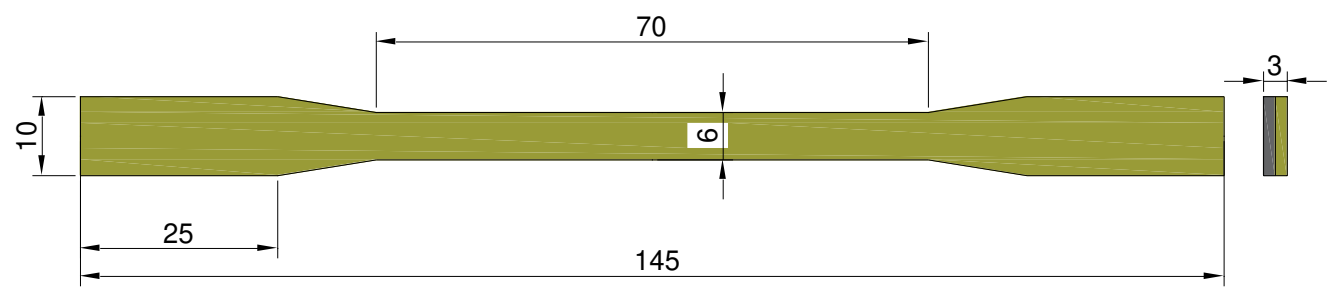

(a) Tensile specimen 


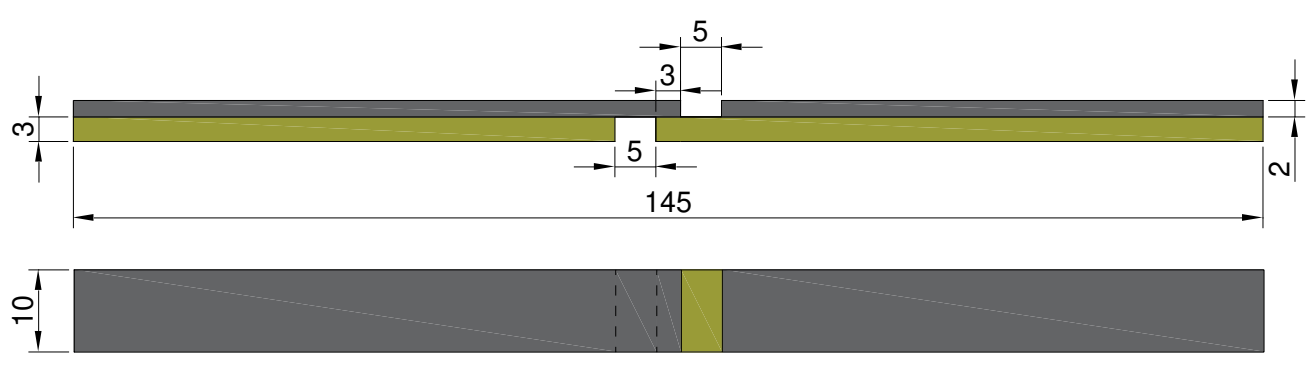

(b) Tensile-shear specimen

Fig.3.3 Size of the specimen

The stress-strain curve of the tensile test is shown in Fig.3.4, it can be seen from the figure that the tensile strength is $484 \mathrm{MPa}$, the tensile strength of steel is $405 \mathrm{MPa}$, and the tensile strength of pure niobium is between $250-350 \mathrm{MPa}[23]$. The tensile strength of the specimen is significantly higher than the two base materials. The failure section of the sample did not appear to crack at the welding interface, and the two metals were disconnected at the same time, which proved that the composite plate obtained by explosive welding of niobium-steel was of better quality.

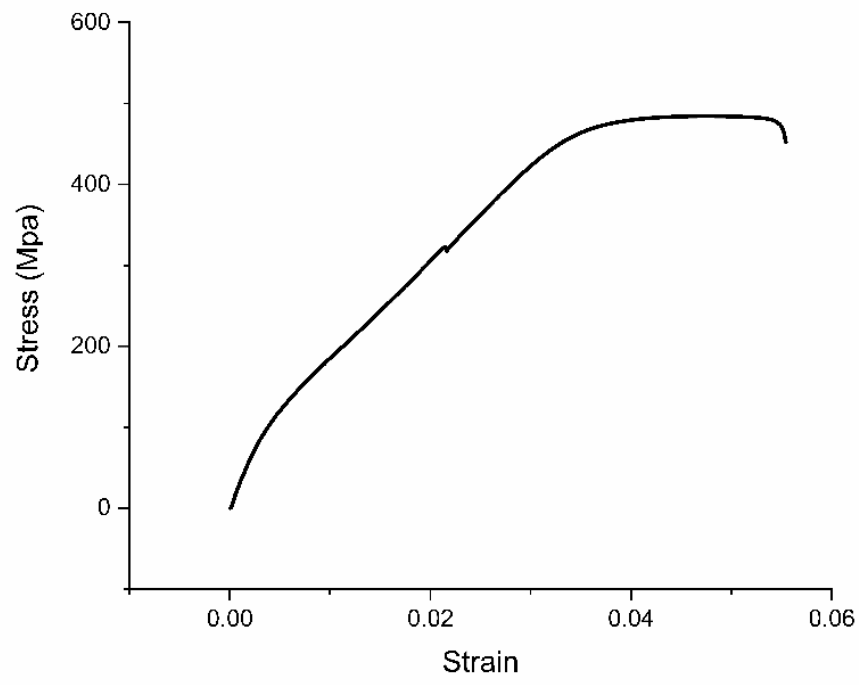

Fig.3.4 The stress-strain curve

Shear strength is one of the important indicators for judging the welding quality of explosive welded composite plates[24]. The shear strength of the welding interface is $174 \mathrm{MPa}$ shown in Fig.3.5 which is the stress-distance curve of the tensile shear test. 


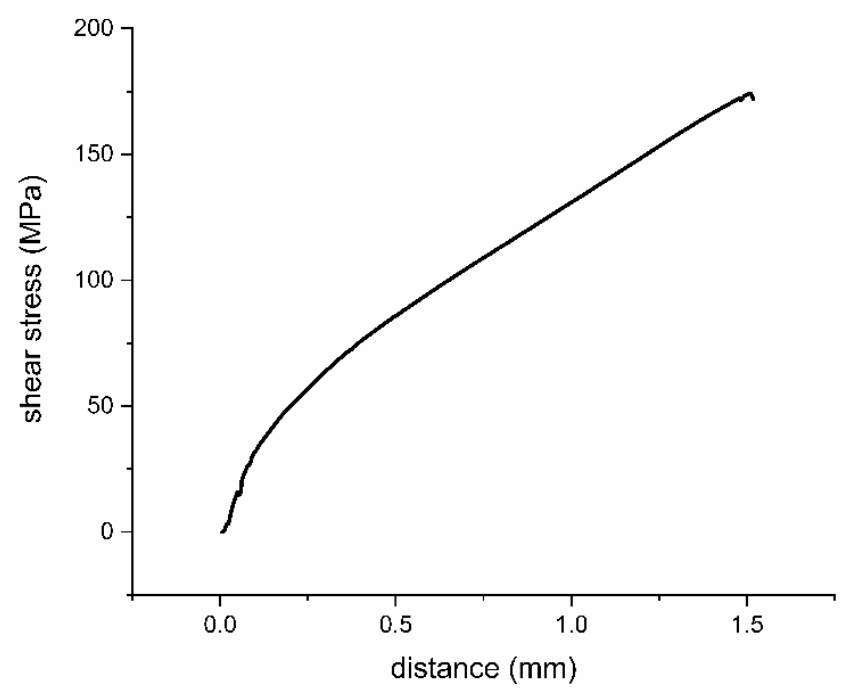

Fig.3.5 The shear stress-distance curve

\section{Numerical Simulation}

Since the formation process of the explosive welding interface is difficult to capture in experiments, commercial finite element software is used to simulate the welding process and the formation of the welding interface. The Smoothed Particle Hydrodynamics is widely used because it can solve the problem of large deformation of the material and can also reproduce the phenomenon of jet and vortex[25,26].

The 2D calculation model was used for saving calculation cost, the length of base plate and flyer plate are both $10 \mathrm{~mm}$. Lagrangian grid and particle coupling method for base plate, coupling of particles of different sizes into flyer plate. Since the size of the particles has an important effect on the formation state of the capture interface and the jet flow, the surface of the two metal plates is set to a thickness of $0.5 \mathrm{~mm}$ and the particle size of $5 \mathrm{um}$. According to the explosion parameters, $\theta=13.88^{\circ}, V_{p}=676 \mathrm{~m} / \mathrm{s}$ calculated by the welding window[27]. The numerical calculation model is shown in Fig.4.1.

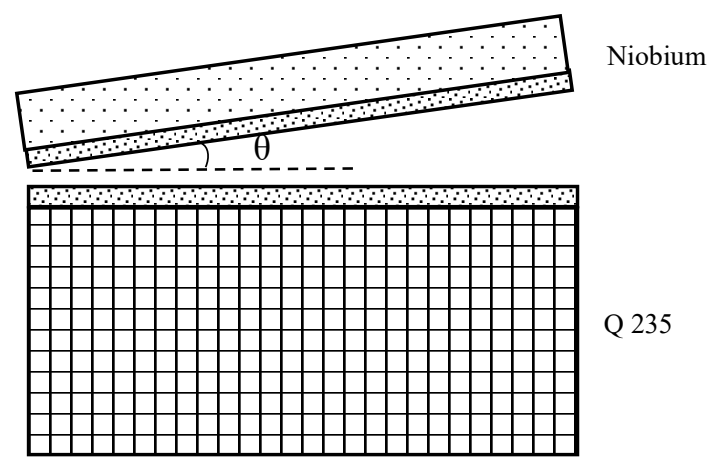

Fig.4.1. Numerical calculation model

The simulation result was shown in Fig.4.2, the welding process was well reproduced. The measured wave length is about $440 \mathrm{um}$, which is consistent with the experimental results. It can be 
seen that the jet is generated, and the generation of jet is also the basic feature of wave formation at the welding interface. It can be seen from the figure that there is a melting zone near the welding interface, which is also consistent with the element analysis record.

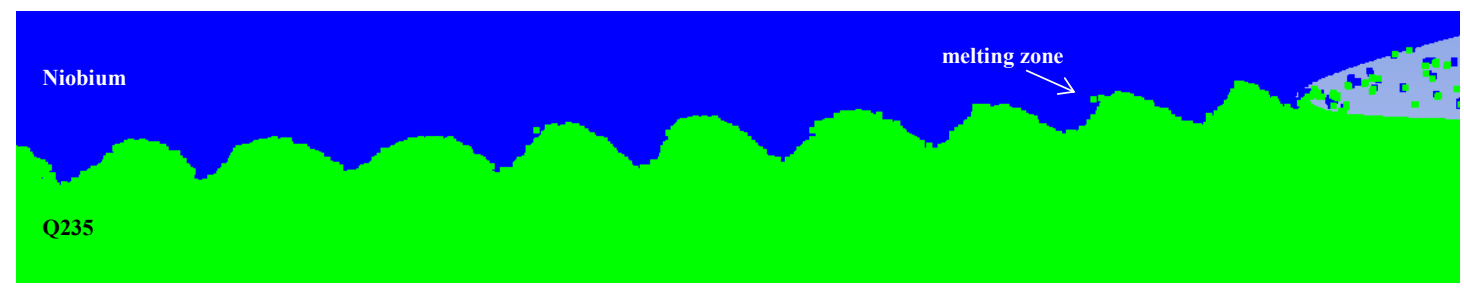

Fig.4.2 The simulation result

The Mises stress distribution of the welding interface was shown in Fig.4.3(a), it can be seen that there are some areas where the stress is zero at the interface due to the material at the interface becomes incompressible fluid under high temperature and high pressure. The shear stress distribution of the welding interface is shown in Fig.4.3(b), The shear stress near the welding interface is higher than other areas, the shear stress of the flyer plate is higher than the base plate. The results are consistent with previous research results[28-29].
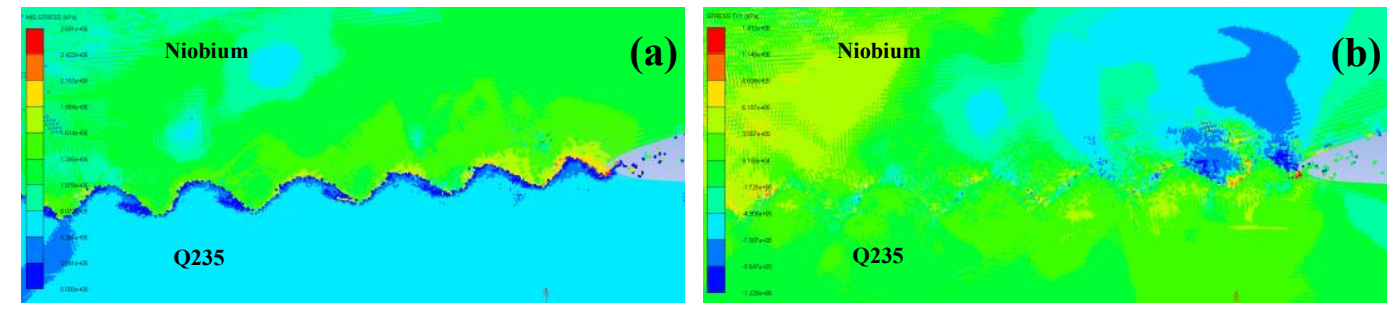

Fig.4.3 The distribution of the welding interface:(a) Mises stress,(b) Shear stress

The interface temperature distribution is shown in the Fig.4.4, it can be seen from the figure that the maximum temperature at the interface will reach above $6000 \mathrm{~K}$, which has exceeded the melting point of steel and niobium. This causes both metals to melt at the interface and form a wavy interface. It also explains the reasons for the existence of the transition zone and the melting zone.

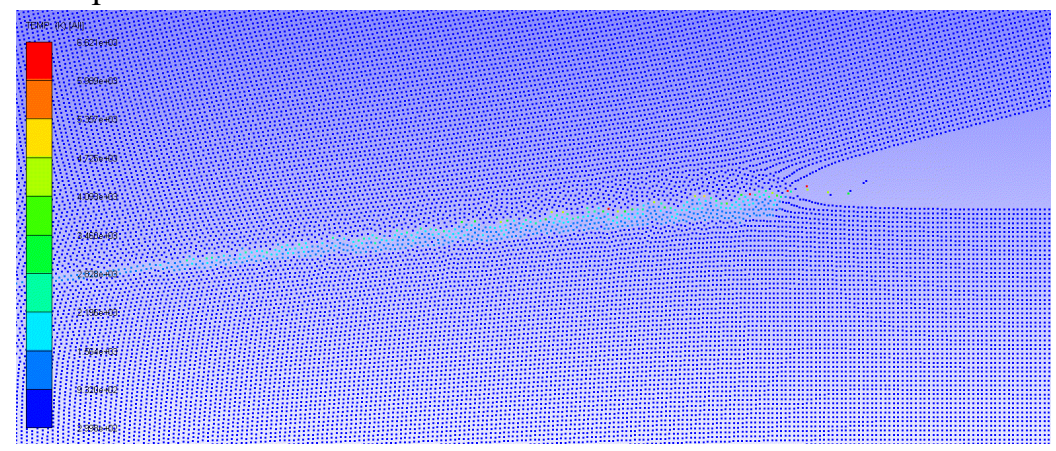

Fig.4.4 Interface Temperature Distribution

\section{Conclusion}

In this work, the explosive welding method was successfully used to produce the niobium-steel 
explosive welding composite plate. The parameters were determined by theoretical analysis and numerical simulation. the specimen interface was observed by SEM and determined the elements by an energy spectrum analyzer, the mechanical properties of the specimen were tested. The welding process was simulated by the SPH method. And the distribution of pressure, temperature and stress were obtained during the welding process. The following conclusions can be obtained:

[1]. It is an effective method that parameters calculated by explosive window were used to produce niobium-steel explosive composite plate. Explosive parameters were chosen as follows: the detonation velocity $\mathrm{V}_{d}=2800 \mathrm{~m} / \mathrm{s}$, the explosive thickness $\delta_{0}=30 \mathrm{~mm}$, the density $\rho_{0}=0.9 \mathrm{~g} / \mathrm{cm}^{3}$.

[2]. Corrosion to niobium first, then to steel, can get a better corrosion interface. When the detonation parameters were selected appropriately, the interface of the niobium-steel explosive welding composite plate has a good microwave structure without holes or cracks, the thickness of the diffusion layer between the two metals is $5 \mathrm{um}$.

[3]. The tensile strength of the composite plate is $484 \mathrm{MPa}$, which is higher than the base materials, and the shear strength of the welding interface is $174 \mathrm{MPa}$.

[4]. The interface wave obtained by the numerical simulation is consistent with the experimental results. The zero Mises stress at the welding interface also proves that the material at the interface is a fluid model. The sign of the interface shear stress is opposite, which also proves that the welding quality is better. The interface temperature can reach above $6000 \mathrm{~K}$, that can cause the two metals to melt.

\section{Declarations}

Funding: The work described in this paper was fully supported by a grant from the National Natural Science Foundation of China (No.1207021002) by Xiaojie Li.

Conflicts of interest/Competing interests:we declare that we have no known competing financial interests or personal relationships that could have appeared to influence the work reported in this paper.

Availability of data and material: Data and materials are completely transparent.

Code availability: None.

Authors' contributions: The author's contribution is the calculation of theoretical data in the early stage of the experiment and the processing and analysis of experimental results.

\section{References}

[1]. Parchuri, PradeepK., et al. "Benefits of Intermediate-Layer Formation at the Interface of $\mathrm{Nb} / \mathrm{Cu}$ and $\mathrm{Ta} / \mathrm{Cu}$ Explosive Clads." Materials \& Design, vol. 166, 2019, p. 107610. https://doi.org/10.1016/j.matdes.2019.107610

[2]. Zeng, Xiang-yu, et al. "Numerical Study on the Effect of Thermal Conduction on Explosive Welding Interface.” The International Journal of Advanced Manufacturing Technology, vol. 
104, no. 5, 2019, pp. 2607-2617. https://doi.org/10.1007/s00170-019-04054-w

[3]. Zeng, Xiang-yu, et al. "Effect of Inert Gas-Shielding on the Interface and Mechanical Properties of Mg/Al Explosive Welding Composite Plate." Journal of Manufacturing Processes, vol. 45, 2019, pp. 166-175. https://doi.org/10.1016/j.jmapro.2019.07.007

[4]. Yan, Y. B., et al. "Microstructure and Properties of Magnesium AZ31B-aluminum 7075 Explosively Welded Composite Plate." Materials Science and Engineering A-Structural Materials Properties Microstructure and Processing, vol. 527, no. 9, 2010, pp. 2241-2245. https://doi.org/10.1016/j.msea.2009.12.007

[5]. Mali, V. I., et al. "Microstructure and Mechanical Properties of Ti/Ta/Cu/Ni Alloy Laminate Composite Materials Produced by Explosive Welding." The International Journal of Advanced Manufacturing Technology, vol. 93, no. 9, 2017, pp. 4285-4294. https://doi.org/10.1007/s00170-017-0887-8

[6]. Manikandan, P., et al. "Underwater Explosive Welding of Thin Tungsten Foils and Copper." Journal of Nuclear Materials, vol. 418, no. 1, 2011, pp. 281-285. https://doi.org/10.1016/j.jnucmat.2011.07.013

[7]. Zhou, Guoan, et al. "Microstructure and Mechanical Properties of Simultaneously Explosively-Welded Steel/Cu Pipes and Al/Cu Pipe/Rod.” Journal of Manufacturing Processes, vol. 47, 2019, pp. 244-253. https://doi.org/10.1016/j.jmapro.2019.10.004

[8]. Carvalho, G. H. S. F. L., et al. "Explosive Welding of Aluminium to Stainless Steel Using Carbon Steel and Niobium Interlayers." Journal of Materials Processing Technology, vol. 283, 2020, p. 116707. https://doi.org/10.1016/j.jmatprotec.2020.116707

[9]. Carvalho, G. H. S. F. L., et al. "Weldability of Aluminium-Copper in Explosive Welding." The International Journal of Advanced Manufacturing Technology, vol. 103, no. 5, 2019, pp. 32113221. https://doi.org/10.1007/s00170-019-03841-9

[10].Arab, Ali, et al. "Joining AlCoCrFeNi High Entropy Alloys and Al-6061 by Explosive Welding Method." Vacuum, vol. 174, 2020, p. 109221. https://doi.org/10.1016/j.vacuum.2020.109221

[11]. Yang, Ming, et al. "Dissimilar Material Welding of Tantalum Foil and Q235 Steel Plate Using Improved Explosive Welding Technique.” Materials \& Design, vol. 186, 2020, p. 108348. https://doi.org/10.1016/j.matdes.2019.108348

[12]. Wang, Qi, et al. "Experimental and Numerical Studies on Preparation of Thin AZ31B/AA5052 Composite Plates Using Improved Explosive Welding Technique.” Metals, vol. 10, no. 8, 2020, p. 1023. https://doi.org/10.3390/met10081023

[13].Bataev, I. A., et al. "Metallic Glass Formation at the Interface of Explosively Welded $\mathrm{Nb}$ and Stainless Steel." Metals and Materials International, vol. 21, no. 4, 2015, pp. 713-718. https://doi.org/10.1007/s12540-015-5020-7

[14].Li, Yan, et al. "Numerical Simulation of Ti/Al Bimetal Composite Fabricated by Explosive Welding." Metals, vol. 7, no. 10, 2017, p. 407. https://doi.org/10.3390/met7100407

[15].Athar, M. M.Hoseini, and Behzad Tolaminejad. "Weldability Window and the Effect of Interface Morphology on the Properties of $\mathrm{Al} / \mathrm{Cu} / \mathrm{Al}$ Laminated Composites Fabricated by Explosive Welding." Materials \& Design, vol. 86, 2015, pp. 516-525. https://doi.org/10.1016/j.matdes.2015.07.114

[16].Hoseini-Athar, M. M., and B. Tolaminejad. "Interface Morphology and Mechanical Properties of Al-Cu-Al Laminated Composites Fabricated by Explosive Welding and Subsequent Rolling Process." Metals and Materials International, vol. 22, no. 4, 2016, pp. 670-680. 
https://doi.org/10.1007/s12540-016-5687-4

[17].Émurlaeva Y Y, Bataev I A, Zhou Q, et al. Welding window: Comparison of deribas' and wittman's approaches and SPH simulation results[J]. Metals, 2019, 9(12): 1323. https://doi.org/10.3390/met9121323

[18].Blazynski, T. Z. Explosive Welding, Forming and Compaction. 1983. Reference to a chapter in an edited book.

[19]. Wittman R H. The influence of collision parameters of the strength and microstructure of an explosion welded aluminium alloy[J]. Proc. 2nd Int. Sym. on Use of an Explosive Energy in Manufacturing Metallic Materials, 1973: 153-168.

[20]. Yang, Ming, et al. "Study on Explosive Welding for Manufacturing Meshing Bonding Interface of CuCrZr to 316L Stainless Steel.” Fusion Engineering and Design, vol. 143, 2019, pp. $106-$ 114. https://doi.org/10.1016/j. fusengdes.2019.03.137

[21].Paul H, Miszczyk M M, Chulist R, et al. Microstructure and phase constitution in the bonding zone of explosively welded tantalum and stainless steel sheets[J]. Materials \& Design, 2018, 153: 177-189. https://doi.org/10.1016/j.matdes.2018.05.014

[22].Zhang T, Wang W, Zhang W, et al. Microstructure evolution and mechanical properties of an AA6061/AZ31B alloy plate fabricated by explosive welding[J]. Journal of Alloys and Compounds, 2018, 735: 1759-1768. https://doi.org/10.1016/j.jallcom.2017.11.285

[23]. Oliveira J P, Panton B, Zeng Z, et al. Laser joining of NiTi to Ti6A14V using a Niobium interlayer[J]. Acta Materialia, 2016, 105: 9-15. https://doi.org/10.1016/j.actamat.2015.12.021

[24].Chen, Pengwan, et al. "Investigation on the Explosive Welding of 1100 Aluminum Alloy and AZ31 Magnesium Alloy." Journal of Materials Engineering and Performance, vol. 25, no. 7, 2016, pp. 2635-2641. https://doi.org/10.1007/s11665-016-2088-2

[25].Zhou, Qiang, et al. "Numerical and Experimental Studies on the Explosive Welding of Tungsten Foil to Copper." Materials, vol. 10, no. 9, 2017, p. 984. https://doi.org/10.3390/ma10090984

[26].Liu, M. B., et al. "A Density-Adaptive SPH Method with Kernel Gradient Correction for Modeling Explosive Welding." Computational Mechanics, vol. 60, no. 3, 2017, pp. 513-529. https://doi.org/10.1007/s00466-017-1420-5

[27].Ribeiro, J. B., et al. "Review of the Weldability Window Concept and Equations for Explosive Welding." Journal of Physics: Conference Series, vol. 500, no. 5, 2014, p. 52038. https://doi.org/10.1088/1742-6596/500/5/052038

[28].Wang, X.; Zheng, Y .; Liu, H.; Shen, Z.; Hu, Y .; Li, W.; Gao, Y .; Guo, C. Numerical study of the mechanism of explosive/impact welding using Smoothed Particle Hydrodynamics method. Mater. Des. 2012, 35, 210-219. https://doi.org/10.1016/j.matdes.2011.09.047

[29].Mousavi, A. A.Akbari, et al. "Simulation of Explosive Welding Using the Williamsburg Equation of State to Model Low Detonation Velocity Explosives." International Journal of Impact Engineering, vol. 31, no. 6, 2005, pp. 719-734. https://doi.org/10.1016/j.ijimpeng.2004.03.003 
Figures

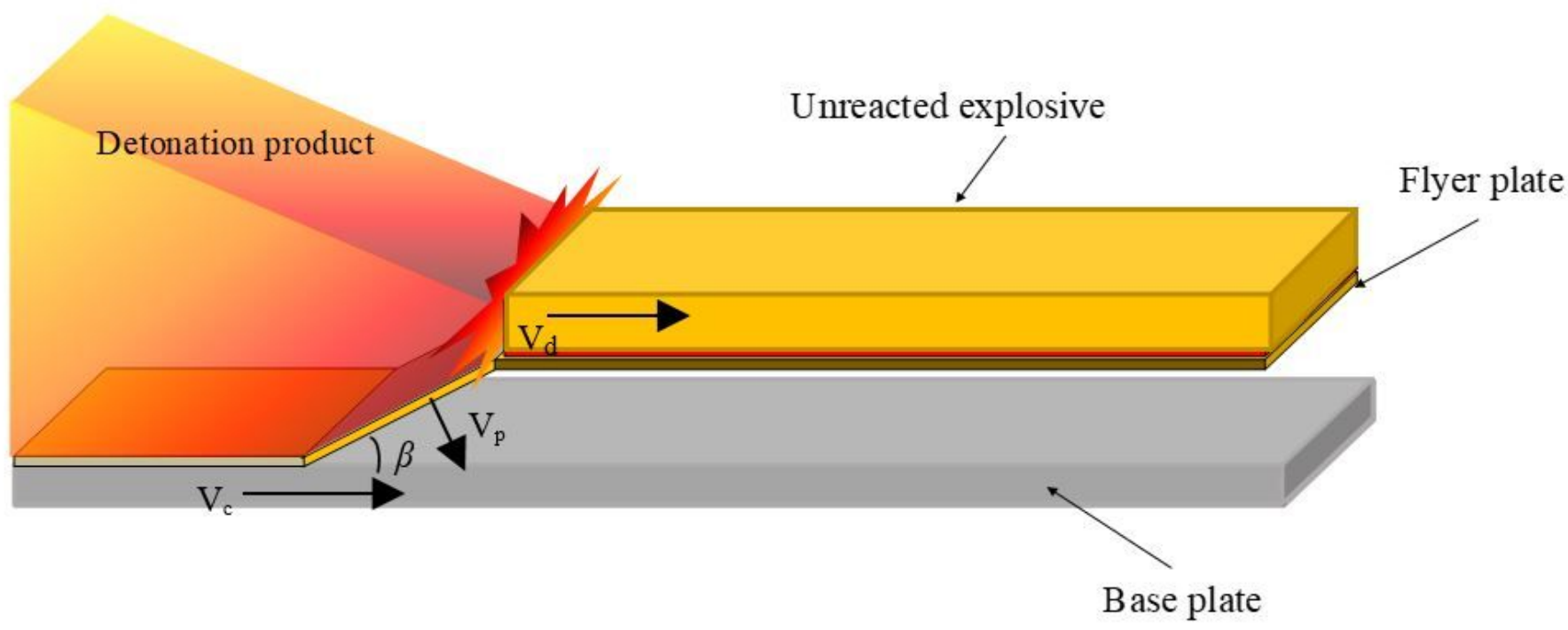

\section{Figure 1}

Schematic diagram of explosive welding process 


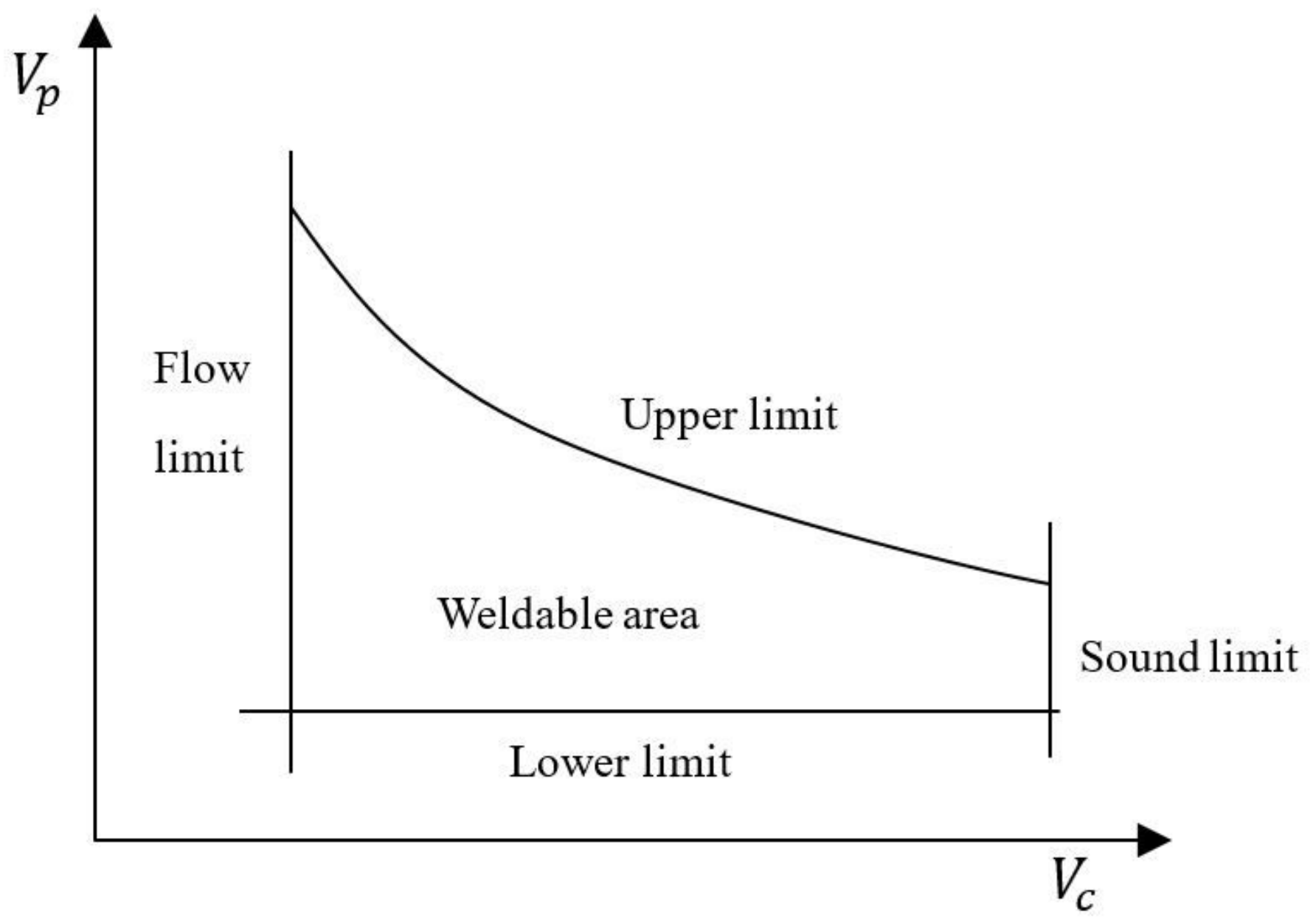

Figure 2

Explosive welding window 


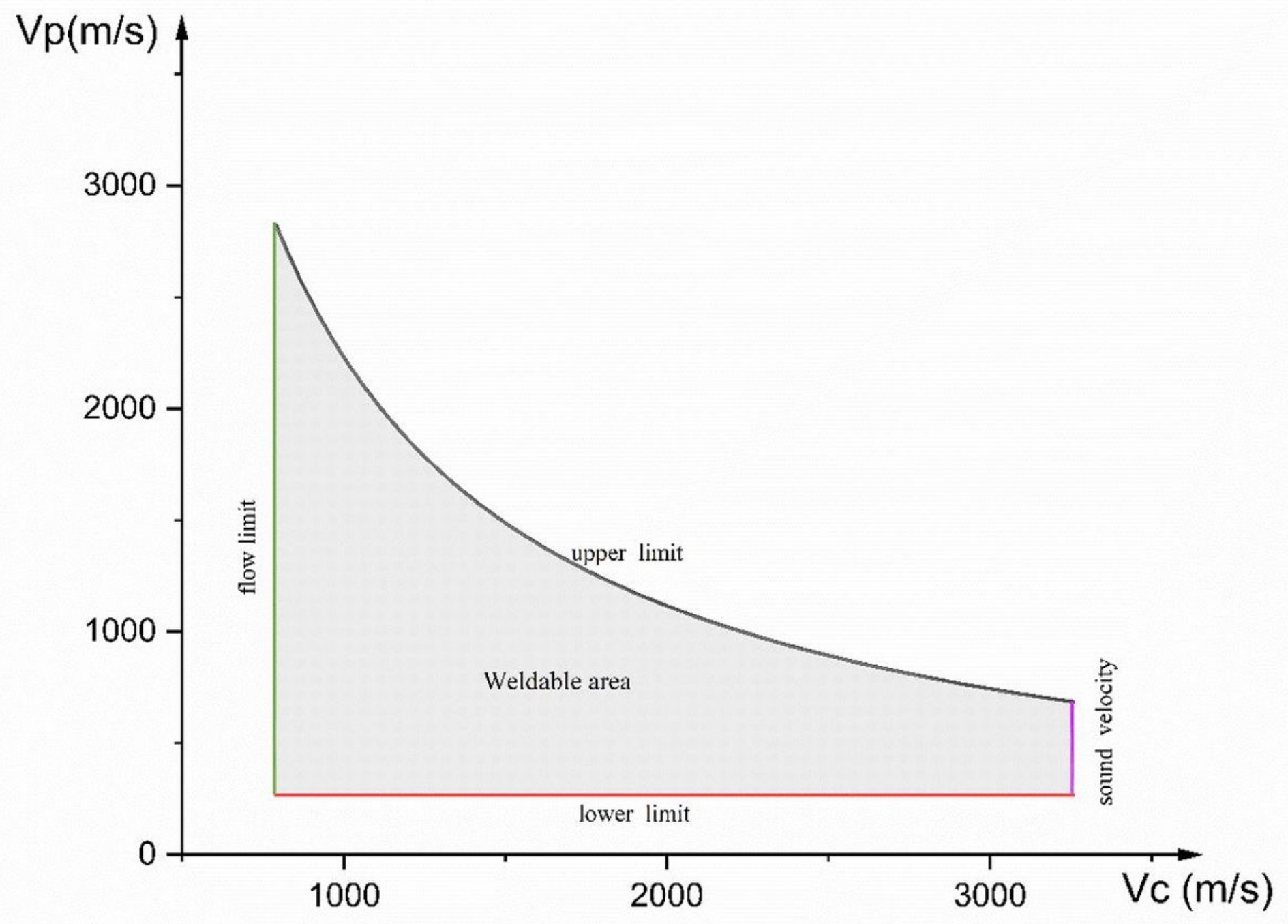

Figure 3

Niobium-Steel explosive welding window 


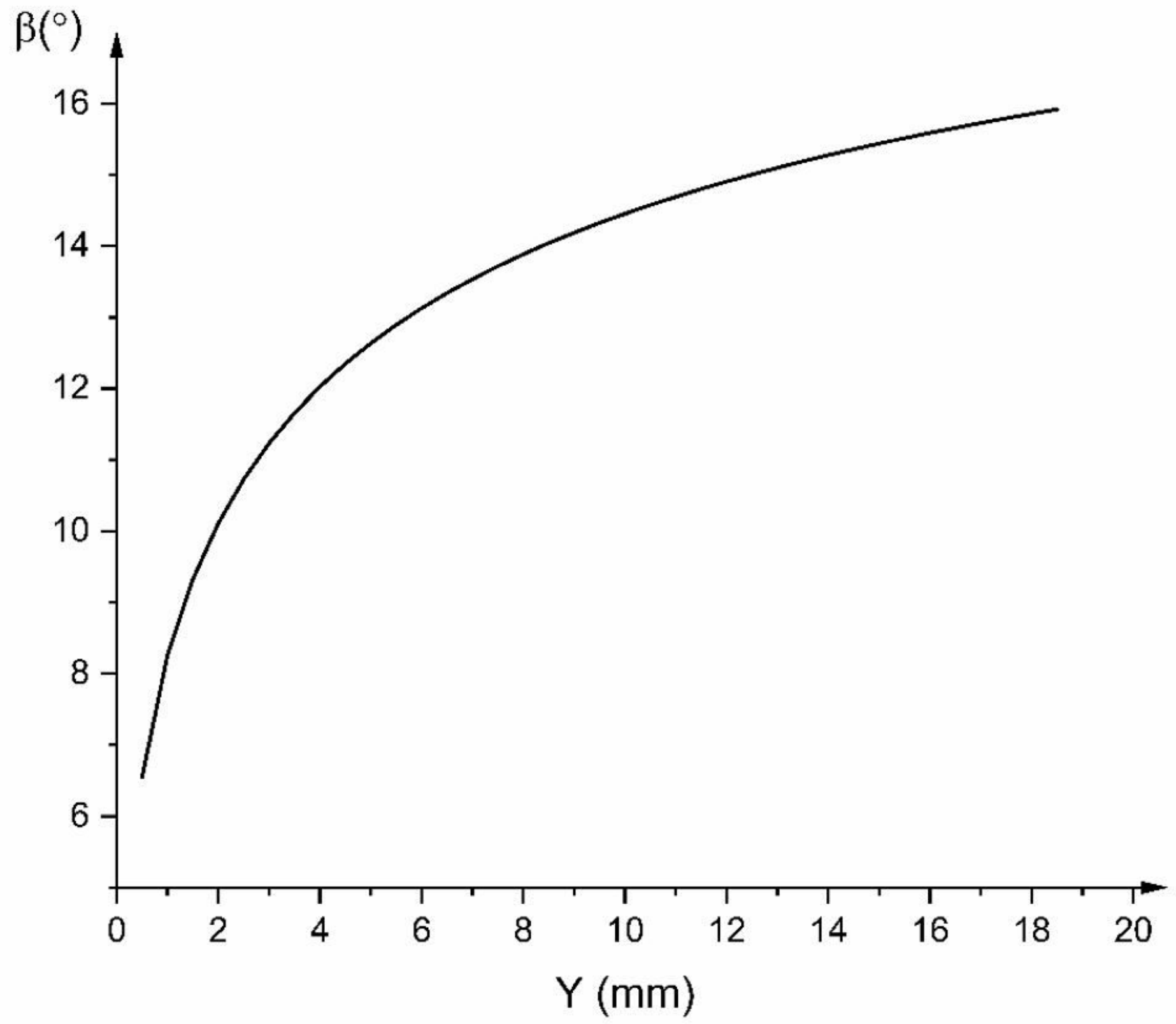

Figure 4

The relationship between y and $\beta$ 

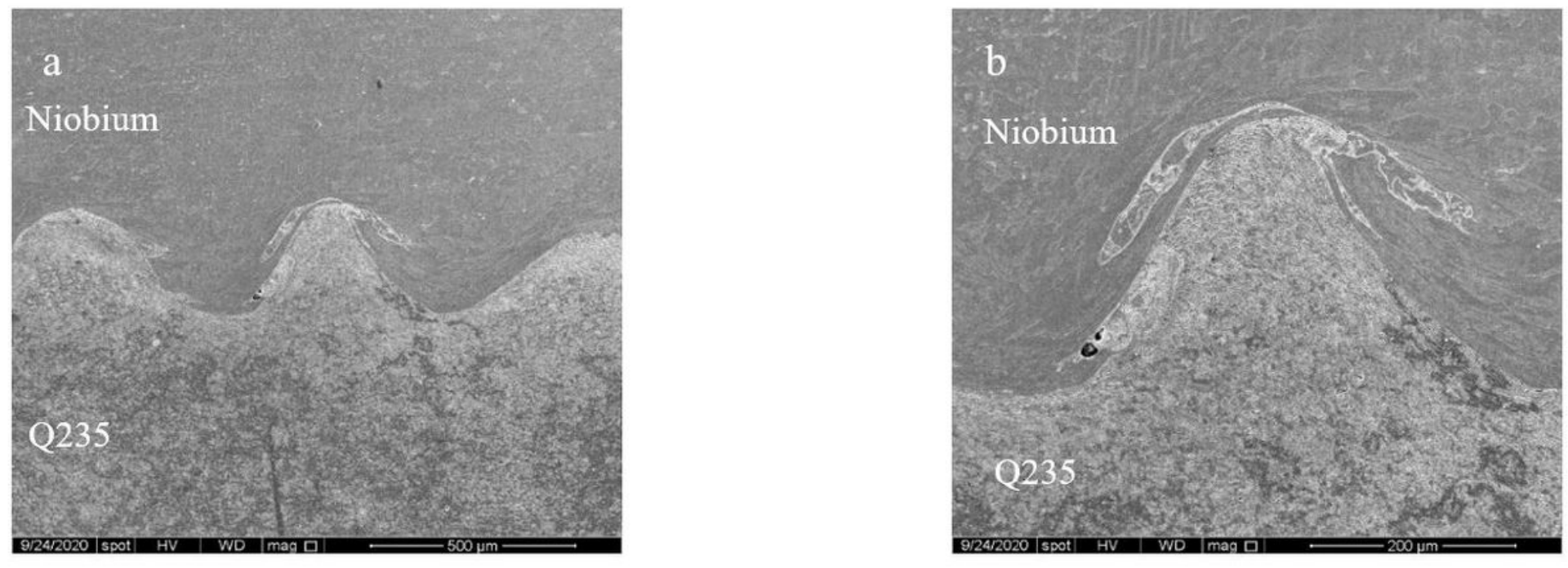

\section{Figure 5}

SEM image of Niobium-Q235 interface

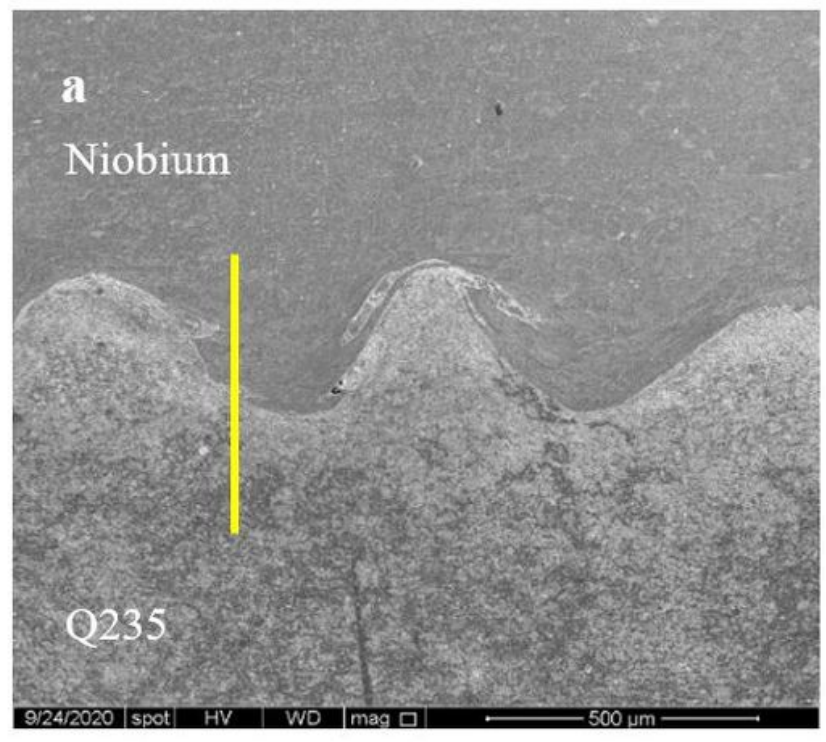

b

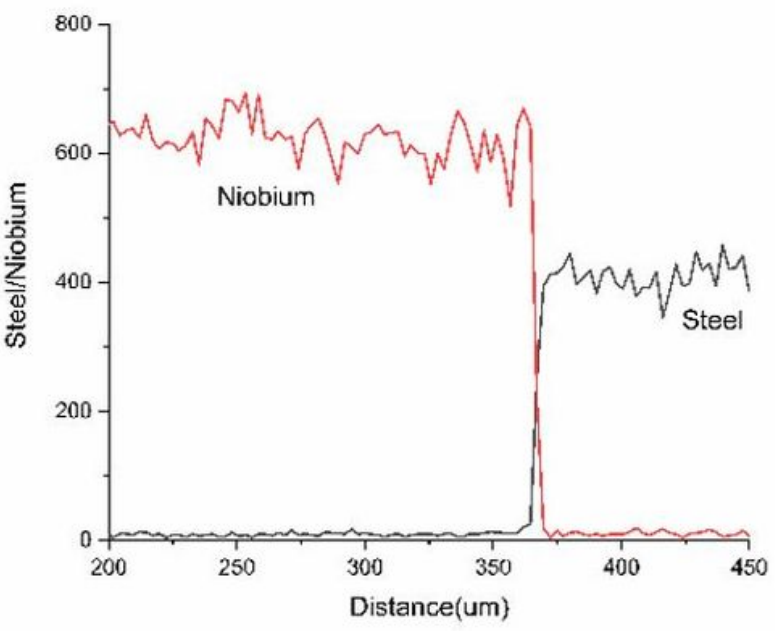

Figure 6

Elemental analysis image of Niobium-Q235 interface 


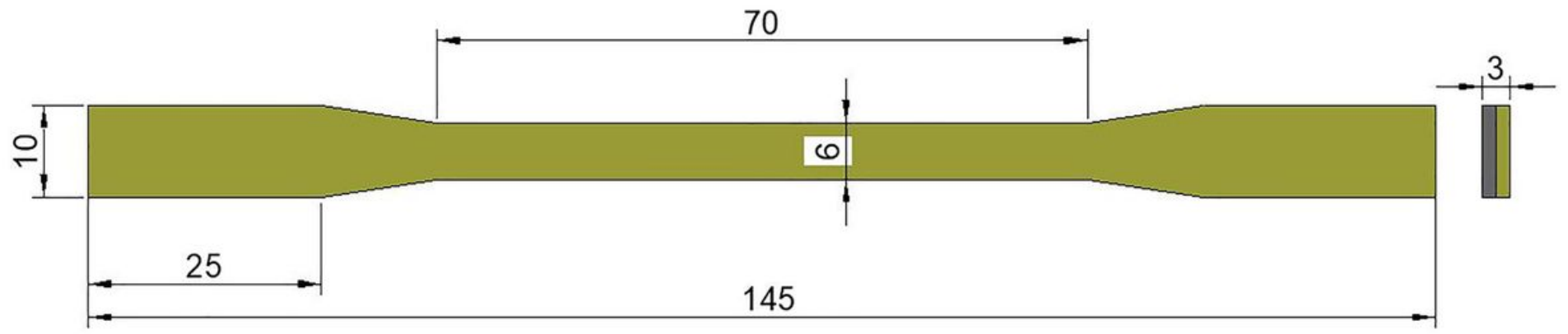

(a) Tensile specimen
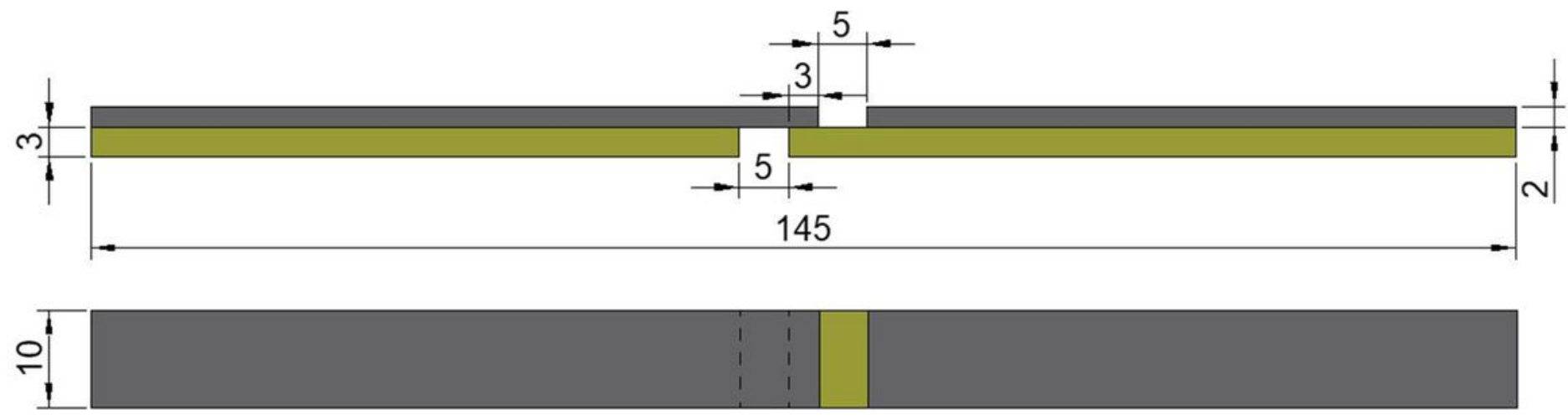

(b) Tensile-shear specimen

Figure 7

Size of the specimen 


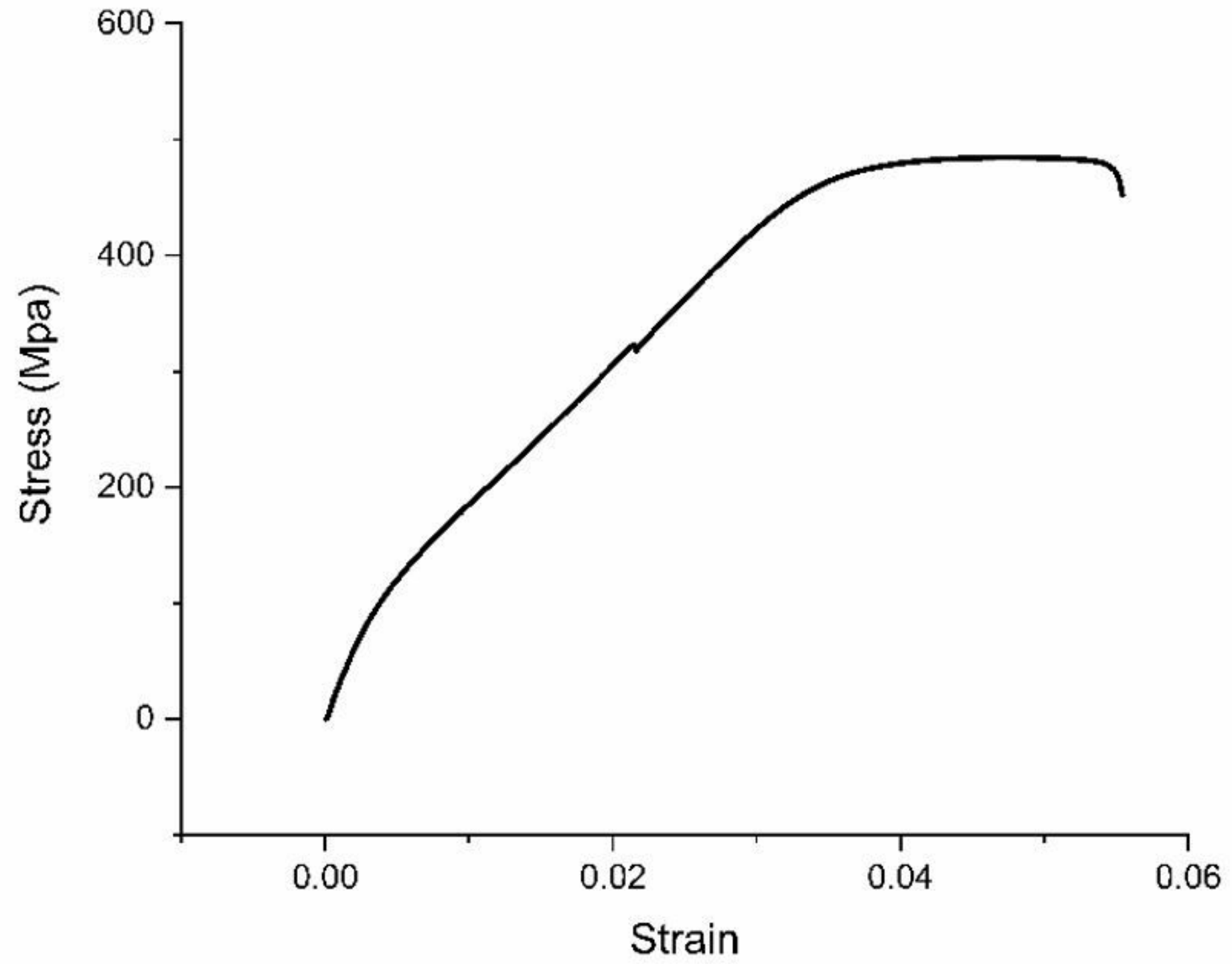

Figure 8

The stress-strain curve 


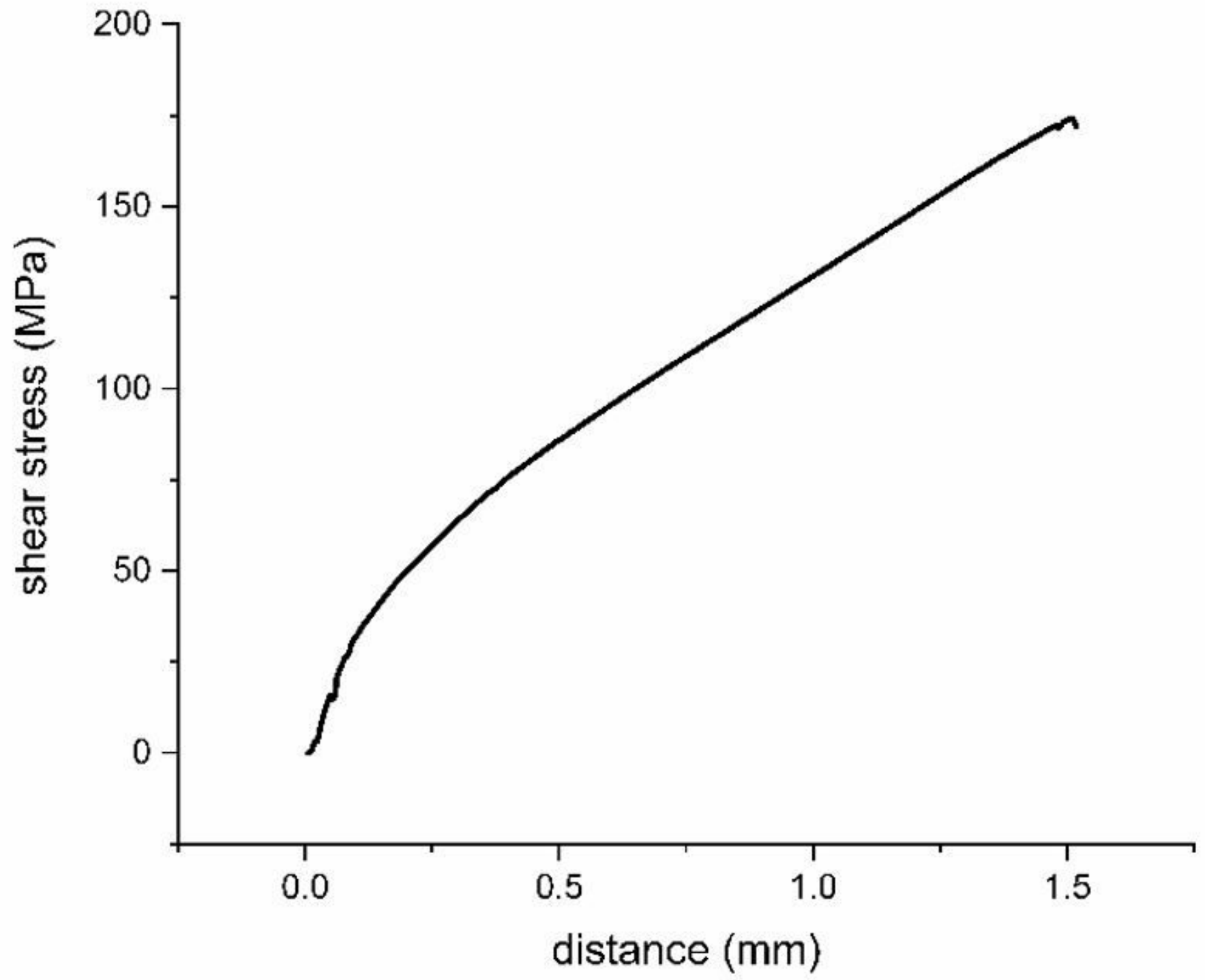

Figure 9

The shear stress-distance curve 


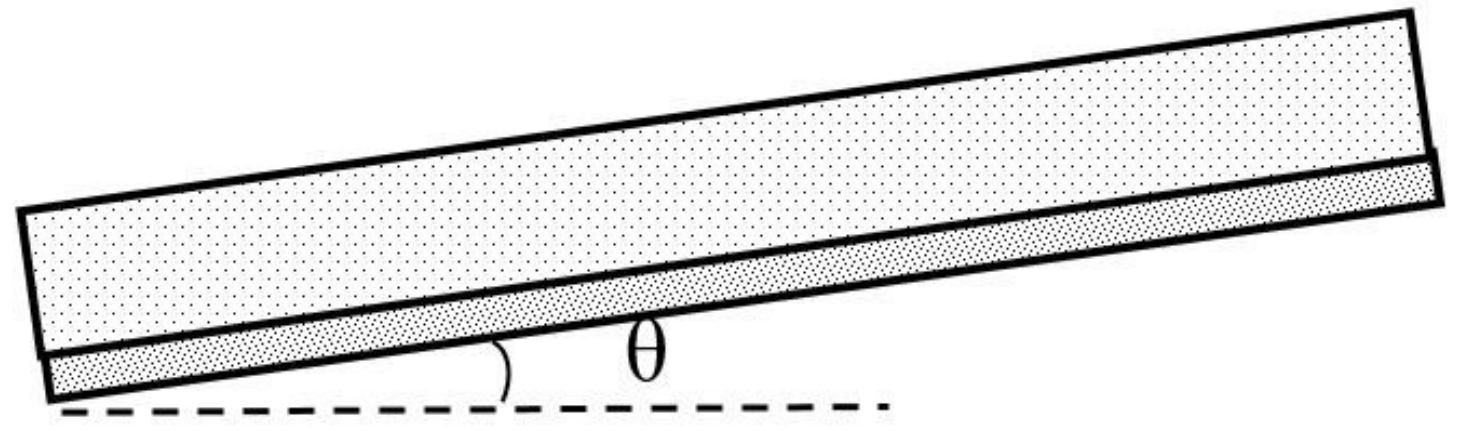

Niobium

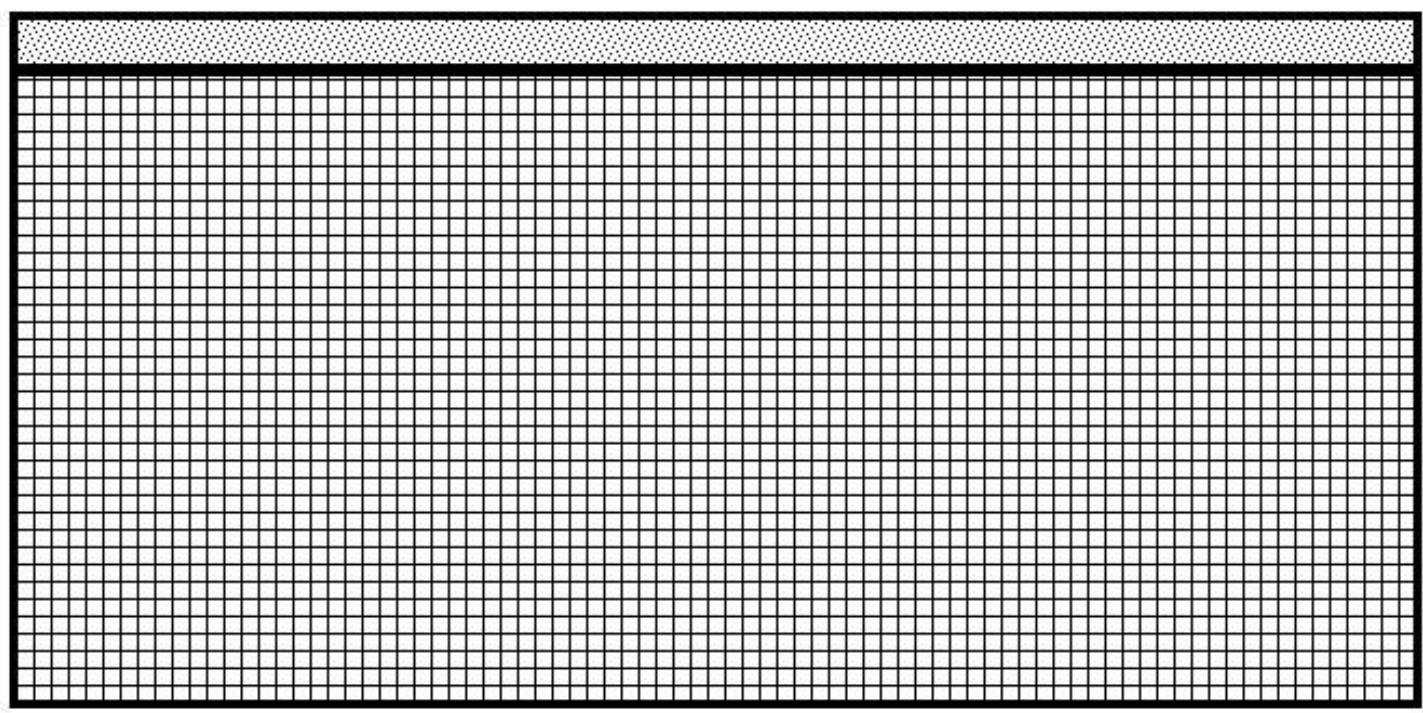

Q 235

Figure 10

Numerical calculation model

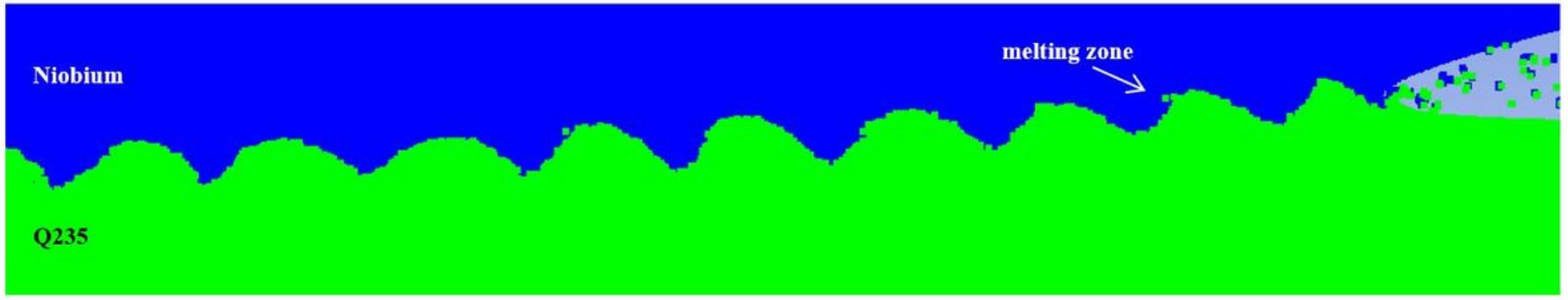

Figure 11

The simulation result 

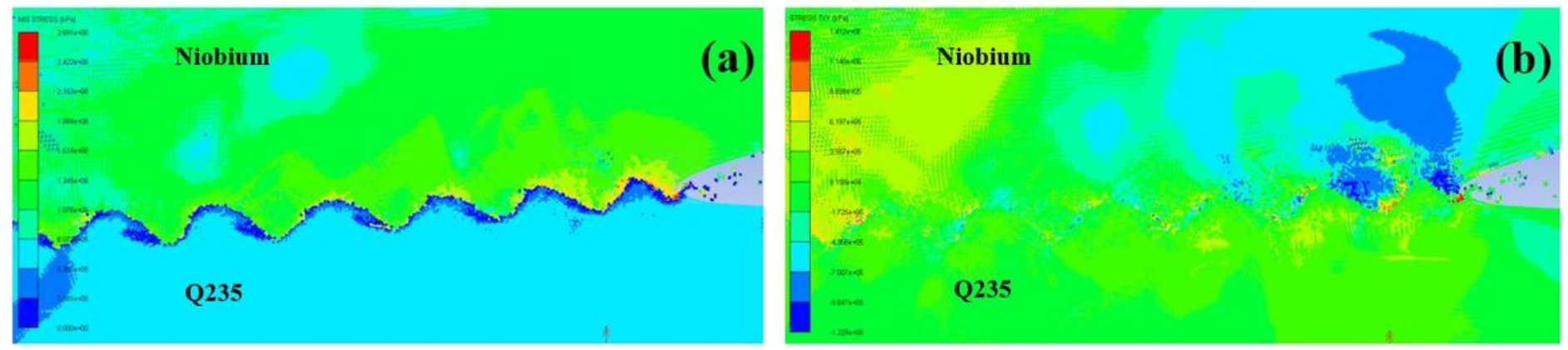

Figure 12

The distribution of the welding interface:(a) Mises stress,(b) Shear stress

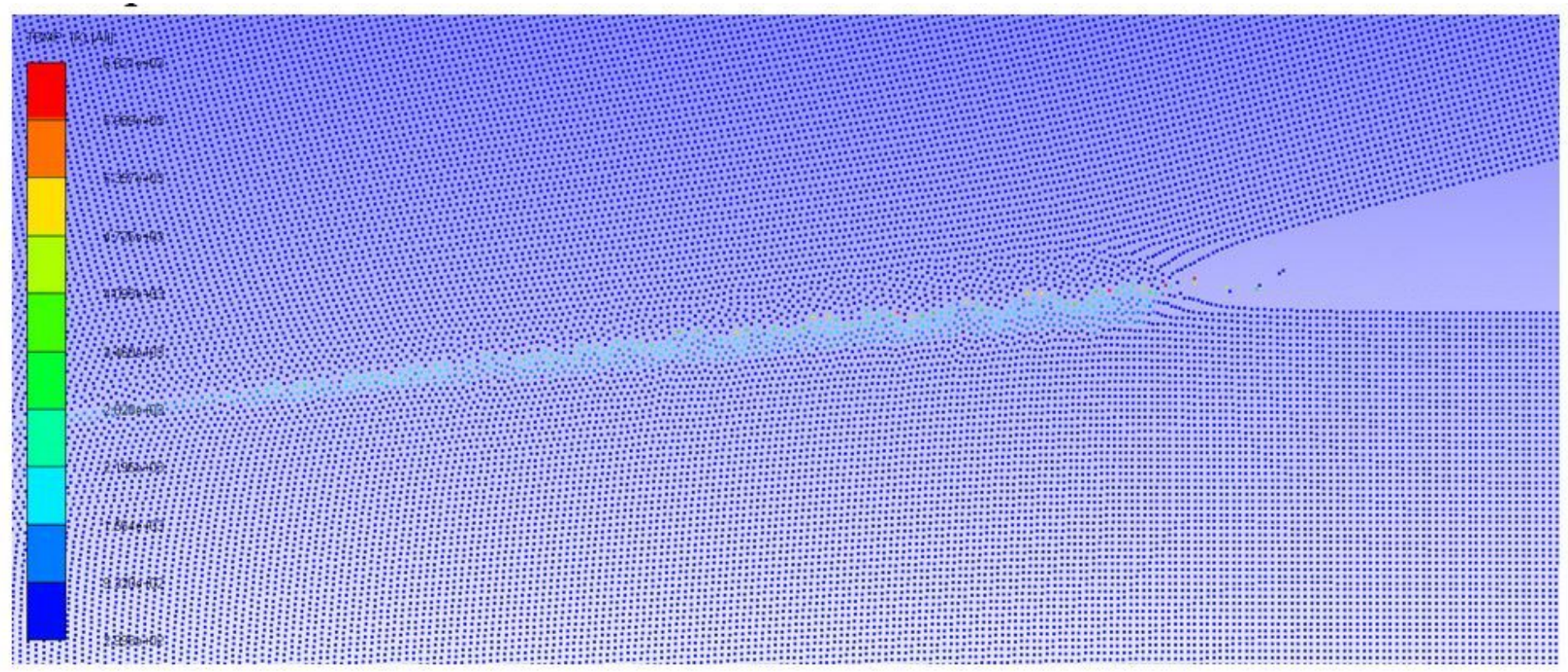

Figure 13

Interface Temperature Distribution 